\title{
Los convenios interadministrativos en el ordenamiento jurídico español desde un punto de vista contractual
}

Marc Vilalta-ReiXaCH ${ }^{1}$

\section{RESUMEN}

Este trabajo tiene por objeto analizar el tratamiento contractual que reciben los convenios entre administraciones públicas territoriales en el ordenamiento jurídico español. A tal efecto se examina, en primer lugar, la posibilidad de considerar dichos convenios como contratos públicos bajo el Texto refundido de la Ley de Contratos del Sector Público; para pasar a cuestionar, seguidamente, qué consecuencias prácticas pueden derivarse de esta consideración y la conveniencia de someter estas relaciones convencionales a la normativa contractual.

Palabras clave: convenios interadministrativos, contratos públicos, negocios excluidos del Texto refundido de la Ley de Contratos del Sector Público, ordenamiento jurídico español, colaboración administrativa.

1 Doctor en Derecho, Universidad de Barcelona, Barcelona, España. Profesor agregado de Derecho Administrativo, Universitat Oberta de Catalunya (UOC), Barcelona, España. Sus principales líneas de investigación son las relaciones interadministrativas, el derecho local y la contratación pública. Correo-e: mvilaltare@uoc.edu. Fecha de recepción: 27 de noviembre de 2015. Fecha de modificación: 15 de abril de 2016. Fecha de aceptación: 16 de mayo de 2016. Para citar el artículo: Vilalta-Reixach, M. (2016). Los convenios interadministrativos en el ordenamiento jurídico español desde un punto de vista contractual. Revista digital de Derecho Administrativo n. ${ }^{\circ}$ 15, primer semestre, Universidad Externado de Colombia, pp. 83-114. DOI: http://dx.doi.org/10.18601/21452946.n15.06 


\title{
Inter-Administrative Agreements in the Spanish Legal System from a Contractual Standpoint
}

\begin{abstract}
The purpose of this paper is to analyze the contractual procedure and treatment that inter-administrative agreements receive in the Spanish legal system. In order to do so, first there is the need to consider such agreements, as instructed by the TRLCSP, as public contracts. Then the paper examines the practical consequences that can derive from this qualification and the convenience of submitting these agreements to the standard contractual regulation in the TRLCSP.

Keywords: Inter-administrative Agreements, Public Works Contracts, Public Sector, Business Transactions Excluded from the TRLCSP, Spanish Legal System, Administrative Cooperation.
\end{abstract}

\section{INTRODUCCIÓN}

Sin duda alguna, los mecanismos de colaboración entre las diferentes entidades públicas territoriales constituyen una pieza clave del sistema administrativo español. En efecto, partiéndose de la consideración de que en muchas ocasiones la satisfacción del interés general no puede ser asumida de una forma totalmente autónoma e independiente por los distintos niveles de gobierno y administración, se ha puesto de relieve la necesidad de establecer mecanismos relacionales entre ellos. Mecanismos que, además de contribuir a dotar de coherencia y unidad al sistema, deben permitir garantizar una gestión eficaz de los intereses públicos.

En este sentido, el ordenamiento jurídico español ha venido regulando una gran variedad de instrumentos o técnicas de colaboración, tanto de carácter orgánico (como los consorcios, mancomunidades de municipios u otras fórmulas asociativas) como funcional (como el deber de asistencia y auxilio entre administraciones públicas o el necesario intercambio de información). Instrumentos que, además, adquieren aún una mayor importancia en el actual contexto de crisis económica, por cuanto pueden verse también como medidas de ahorro que, generando economías de escala, permitan reducir los costes de producción y propiciar un mejor aprovechamiento de los recursos públicos.

En este escenario, nuestro trabajo centrar la atención específicamente en la figura de los convenios entre administraciones públicas que, como se ha afirmado por la doctrina (p. ej., Rodríguez de Santiago, 1997, p. 19), se han convertido en la técnica de colaboración por excelencia, deviniendo en una 
verdadera forma de administrar asuntos de interés común ${ }^{2}$. Ahora bien, nuestro propósito no es ofrecer una exposición completa y detallada de su régimen jurídico, sino centrarnos en un aspecto mucho más concreto: el análisis de dichos instrumentos relacionales desde un punto de vista contractual.

A primera vista podría pensarse, y con razón, que la asociación de estas dos ideas -colaboración y contratación- es completamente equivocada. Y es que tradicionalmente el recurso a mecanismos colaborativos se ha venido considerando como una forma de provisión de bienes o servicios alternativa a la contratación externa. De ahí que la legislación española en materia de contratación viniera excluyendo de su ámbito de aplicación las relaciones de colaboración entre administraciones públicas ${ }^{3}$.

Ahora bien, como veremos en las páginas siguientes, actualmente la frontera entre la colaboración administrativa y el mercado (o la contratación pública) no es tan nítida. Más bien al contrario. La decidida apuesta por la construcción de un mercado interior europeo y la necesidad de asegurar la existencia de un marco jurídico uniforme y sin exclusiones que garantice su funcionamiento han llevado a una notable extensión del ámbito de aplicación de la normativa reguladora de los contratos públicos y, con ella, a la necesidad de precisar en qué casos concretos los acuerdos celebrados entre entidades públicas territoriales deben quedar sujetos a dichas normas ${ }^{4}$. Y es que -tal y como puso claramente de relieve el Tribunal de Justicia de la Unión Europea (en adelante, TJUE) en Sentencia de 13 de enero de 2005, asunto C-84/03, Comisión de las Comunidades Europeas/Reino de España- hoy en día no resulta posible excluir, a priori, dichos instrumentos relacionales. Sino que, en la medida en que estos pudieran configurarse como un mecanismo de adjudicación de determinadas prestaciones a

2 Para hacernos una idea, podemos destacar que sólo en el período 2010-2012 -según los últimos datos publicados por el Registro de Convenios del Ministerio de Hacienda y Administraciones Públicas-y en lo que se refiere a la Administración General del Estado, se suscribieron un total de 883 convenios de colaboración con las entidades locales, en áreas de actuación tan diversas como servicios sociales, economía y hacienda o medio ambiente. Para no remontarnos a antecedentes más lejanos podemos citar, por ejemplo, el artículo 3.1 c) del anterior Real Decreto 2/2000, de 16 de junio, por el que se aprobó el Texto refundido de la Ley de Contratos de las Administraciones Públicas, que excluya del ámbito de aplicación de dicha norma "Los convenios de colaboración que celebre la Administración General del Estado con la Seguridad Social, las Comunidades Autónomas, las Entidades locales, sus respectivos organismos autónomos y las restantes entidades públicas o cualquiera de ellos entre sí".

4 Ciertamente, dada su especial trascendencia en la vida social y económica de los Estados, la contratación pública ha sido uno de los ámbitos en los que la legislación europea ha encontrado un mayor desarrollo; llegándose a conformar, como se ha denominado, un verdadero "Derecho común de los contratos públicos" (RAZQuín LiZARRAGA, 1996, p. 35 o Piñar Mañas, 2004, p. 28). En el mismo sentido se ha afirmado que la aprobación de las directivas europeas en materia de contratación pública viene a consolidar "un proceso de armonización/uniformización jurídica a nivel nacional" (GiMENO FeLiú, 2015, p. 82). 
otra entidad diferenciada, podríamos plantearnos si no estaríamos realmente ante un "contrato público" a efectos de la normativa contractual. De modo que en estos supuestos deberíamos acudir a los procedimientos competitivos de adjudicación previstos en esta.

En todo caso, antes de poder examinar con más detalle todas estas cuestiones resulta imprescindible fijar previamente el punto de partida de nuestra exposición. Esto es, en primer lugar, debemos concretar no sólo a qué nos referimos cuando hablamos de convenios administrativos sino también cuál es la noción de contrato público a efectos de la vigente normativa contractual.

\section{LOS CONVENIOS ENTRE ENTIDADES PÚBLICAS EN EL ORDENAMIENTO JURÍDICO ESPAÑOL}

A pesar de la notable atención que han suscitado en la doctrina administrativista española, y sin perjuicio de lo que diremos más adelante, lo cierto es que hasta el día de hoy no podíamos hablar de la existencia de un concepto legal-siquiera dogmático- de los convenios entre administraciones públicas. Al contrario, se hacía evidente que, en muchas ocasiones, dicha denominación se utilizaba de un modo meramente genérico, sin remitir a un único y preciso concepto (Rodríguez de Santiago, 1997, pp. 95-96). De ahí que, ante la variopinta magnitud de la institución convencional, incluso se llegara a afirmar que los convenios administrativos no existían como categoría jurídica (Bustillo Bolado, 2004, p. 171).

Sin embargo, la recientemente aprobada Ley 40/2015, de 1 de octubre, de Régimen Jurídico del Sector Público (en adelante, LRJSP) -destinada a entrar en vigor en octubre de 2016-, marca un punto de inflexión importante en esta materia. Aunque es cierto que la regulación prevista en la LRJSP no es absolutamente innovadora -sino que se nutre, en gran parte, de la regulación de los convenios de colaboración prevista anteriormente en la Ley 30/1992, de 26 de noviembre, de Régimen Jurídico de las Administraciones Públicas y del Procedimiento Administrativo Común (en adelante, LRJPAC), así como de otras normas autonómicas y locales ${ }^{5}-$ lo cierto es que esta introduce por primera vez en la legislación básica estatal una regulación jurídica completa y una definición legal precisa de lo que debe entenderse por convenio en el ámbito administrativo.

En este sentido, el artículo 47.1 LRJSP establece: "Son convenios los acuerdos con efectos jurídicos adoptados por las Administraciones Públicas, los orga-

5 Una buena muestra de ello la podemos encontrar en los artículos 108-112 de la Ley 26/2010, de 3 de agosto, de Régimen Jurídico y Procedimiento de las Administraciones Públicas de Cataluña. Sobre la regulación de los convenios prevista en dicha norma nos remitimos a Gracia Retortillo y Vilalta Reixach (2012, pp. 686-694). 
nismos públicos y entidades de derecho público vinculadas o dependientes o las Universidades públicas entre sí o con sujetos de derecho privado para un fin común...".

Como puede comprobarse, la nueva regulación sigue partiendo de una noción muy amplia de los convenios. Sin embargo, de su tenor literal nos es posible identificar tres elementos distintivos e indispensables para la existencia de este tipo de negocio jurídico:

a) En primer lugar, su carácter bilateral. En efecto, el artículo 47.1 LRJSP exige en todo caso el acuerdo de voluntades entre dos, o más, sujetos diferenciados; ya sean estos entidades públicas o bien sujetos de derecho privado. De esta manera quedarían fuera de la definición legal como convenios los pactos o acuerdos que pudieran establecerse entre órganos de una misma administración pública.

Como se ha puesto de relieve en otras ocasiones (p. ej., Vilalta Reixach, 2012, pp. 263-265 o Martín Huerta, 2010, p. 62), sin negar la importancia y la juridicidad de las relaciones de funcionamiento que puedan establecerse entre las distintas unidades funcionales dentro de una misma organización administrativa, el hecho de que, por principio, carezcan de personalidad jurídica propia $-y$, por tanto, no puedan ser sujetos de derecho-impide poder calificar dichas relaciones interorgánicas como un negocio jurídico de carácter bilateral.

b) Un segundo elemento característico de los convenios sería su carácter jurídico obligatorio. Aunque es cierto que la doctrina y la jurisprudencia española habían tenido ya ocasión de pronunciarse favorablemente sobre la obligatoriedad de los convenios entre administraciones públicas ${ }^{6}$, lo cierto es que la nueva Ley de Régimen Jurídico del Sector Público viene a reforzar dicha interpretación al prever no sólo que los convenios deben implicar efectos jurídicos para las partes intervinientes (art. 47.1 LRJSP) sino que, además, estos deben ser "concretos y exigibles" (a sensu contrario, ex. art. 47.1 LRJSP).

6 Por lo que se refiere al carácter vinculante de los convenios podemos mencionar, por ejemplo, la Sentencia del Tribunal Constitucional n. ${ }^{\circ} 44 / 1986$, de 17 de abril, en la que, al analizar los elementos diferenciadores de los convenios entre comunidades autónomas al amparo del artículo 145 de la Constitución, se identificaba como uno de ellos su carácter vinculante (FJ 3). Por su parte, la Sala de lo Contencioso Administrativo del Tribunal Supremo también ha hecho referencia a estas cuestiones, entre otras, en la Sentencia n. ${ }^{\circ}$ 278/1987, de 23 de febrero, en la que se señalaba que, al ser aplicables a los convenios interadministrativos los principios esenciales de los negocios jurídicos bilaterales, había que concluir también reconociéndoles fuerza vinculante (FJ 2).

En el ámbito doctrinal se han referido también al carácter jurídico obligatorio de los convenios, entre otros muchos, Martin HuerTa, 2000, pp. 35-37, Rodríguez de Santiago, 1997, pp. 339-349 o Albertí Rovira, 1997, p. 635. 
De este modo, el convenio se nos presenta como un instrumento para formalizar un vínculo jurídico obligatorio entre los sujetos participantes. De ahí también que el artículo 49 LRJSP, al regular su contenido mínimo, prevea que, entre otros aspectos, los convenios deberán concretar las obligaciones y compromisos económicos asumidos por cada una de las partes, así como las consecuencias aplicables en caso de incumplimiento. Por lo demás, es también esta eficacia obligatoria propia de los convenios la que nos permite diferenciar esta figura de todos aquellos otros instrumentos -normalmente denominados Protocolos Generales de Actuación (art. 47.1 LRJSP)- que consistirían en meras declaraciones de intenciones de contenido general o en la expresión de una simple voluntad de actuar con un objetivo común, pero sin que se formalicen compromisos jurídicos concretos y exigibles.

c) Por último, para poder hablar de la existencia de un convenio, la LRJSP exige un último requisito: que dicho acuerdo persiga un "fin común" a la partes intervinientes (art. 47.1 LRJSP). De esta manera se concreta el elemento causal que caracterizaría este tipo de negocios jurídicos. Y es que la finalidad última de dicho acuerdo se sitúa en la colaboración en aras de la consecución de un objetivo común.

Como en el caso anterior, la asunción de esta idea no resulta tampoco totalmente desconocida en nuestro ordenamiento jurídico, puesto que el propio Tribunal Constitucional -p. ej., en la Sentencia n. ${ }^{\circ}$ 95/1986, de 10 de julio- había ya señalado que los convenios no son más que una aplicación del principio de colaboración que caracteriza nuestro modelo de organización territorial (FJ 3). No obstante, como veremos más adelante, creemos que la introducción de esta precisión puede jugar un papel muy importante a la hora de determinar la naturaleza jurídica de esta institución y de analizar la posible sujeción de los convenios entre entidades públicas territoriales a la legislación contractual.

Por lo demás, hay que destacar que este requisito teleológico no quedaría solo como una mera exigencia abstracta, sino que, al amparo del artículo 50.1 LRJSP -que prevé que será necesario que el convenio se acompañe de una memoria justificativa donde se analice su necesidad y oportunidad-, entendemos que las partes al formalizar el convenio deberían concretar expresamente los objetivos de interés público compartidos que se persiguen con su suscripción.

A pesar de que somos conscientes de que se trata de una noción muy amplia de lo que son los convenios, que deja sin determinar muchos de los aspectos básicos de su régimen jurídico, esta definición nos sirve ahora para fijar un punto de referencia conceptual a partir del cual poder articular nuestra exposición. Por lo que, de momento, detengámonos en estas tres ideas generales, que intentaremos ir precisando con mayor rigor a lo largo de nuestro trabajo. 


\section{EL ÁMBITO DE APLICACIÓN OBJETIVO DE LA LEGISLACIÓN CONTRACTUAL: LOS CONTRATOS PÚBLICOS}

Una vez hemos fijado una primera definición de los convenios administrativos a efectos de la LRJSP, debemos dar un paso más y profundizar en el examen de su naturaleza jurídica, especialmente en lo que se refiere al análisis de esta figura desde una óptica contractual. Desde esta perspectiva, en este apartado intentaremos dar una respuesta concreta a las siguientes preguntas: cpuede realmente un convenio entre dos entidades públicas territoriales configurarse como un contrato público a efectos de la normativa contractual? Y, en caso afirmativo, ¿qué tratamiento prevé el vigente Real Decreto Legislativo 3/2011, de 14 de noviembre, por el que se aprueba el Texto refundido de la Ley de Contratos del Sector Público (en adelante, TRLCSP) para estos supuestos?

Para contestar estar pregunta, en primer lugar, debemos tener muy presente cuál es el ámbito objetivo de aplicación de la legislación contractual. Y es que hay que tener en cuenta que, de acuerdo con el artículo 1 TRLCSP, esta solamente tiene por objeto regular la contratación del sector público. En este sentido, el TRLCSP entiende como tales todos los contratos onerosos, cualquiera que sea su naturaleza jurídica, que celebren los entes, organismos y entidades comprendidos en su ámbito de aplicación (art. 2.1 TRLCSP) ${ }^{7}$.

De esta manera se fijan con claridad los elementos necesarios para determinar la aplicabilidad de la normativa contractual, articulándola alrededor de tres elementos: 1) la existencia de un contrato, 2) que tenga carácter oneroso y 3) celebrado por una de las entidades comprendidas dentro del sector público. Estos tres elementos tienen que concurrir de forma acumulativa, de modo que si un determinado negocio jurídico carece simultáneamente de alguno de ellos entonces no podremos hablar de la existencia de un contrato del sector público a efectos del TRLCSP y, por lo tanto, su regulación quedaría fuera del ámbito de aplicación de dicha norma jurídica.

En consecuencia, debemos comenzar este apartado descomponiendo cada uno de estos tres elementos para analizar si la figura de los convenios entre entidades públicas, tal y como los hemos configurado hasta ahora, es susceptible de ser calificada realmente como un contrato del sector público a efectos del TRLCSP.

7 Aunque no podamos detenernos expresamente en esta cuestión, como ha quedado ya apuntado, debemos tener muy presente que la actual regulación española en materia de contratación pública se encuentra claramente condicionada por el derecho europeo -actualmente la Directiva 2014/24/UE, de 26 de febrero-. No sólo porque la normativa española ha incorporado conceptos - como la citada noción de contrato público- provenientes de las normas europeas, sino también porque la legislación española ya sólo puede ser hoy día correctamente interpretada desde el contexto europeo. 


\section{LA NECESARIA EXISTENCIA DE UN CONTRATO}

El primer requisito lógico para poder aplicar el TRLCSP reside en la necesaria existencia de un contrato. Ahora bien, la definición de qué debemos entender como tal es una tarea que el TRLCSP no asume directamente sino que remite a la idea de contrato como una categoría conceptual preexistente. Y es que, como ha puesto de relieve la doctrina administrativista española (p. ej., Martín-Retortillo Baquer, 1996, p. 24 o Bustillo Bolado, 2004, pp. 101-105), en nuestro derecho administrativo no existe un concepto propio de contrato, como categoría jurídica, sino que este se ha construido a partir de los esquemas clásicos del derecho civil.

En este sentido, partiendo de la definición del artículo 1254 CC, podríamos pensar que con el término contrato se hace referencia a todo acuerdo de voluntades entre dos o más personas, dirigido a la configuración, modificación o extinción de un vínculo obligatorio entre ellas. Nos referimos, por tanto, a un concepto muy amplio de contrato -a un supraconcepto, recordando las palabras del profesor Díez-Picazo (Díez-Picazo, 1996, p. 76)-, aplicable no sólo al ámbito privado, sino también a otros sectores de actuación (entre ellos el relativo a la Administración Pública) y que serviría de base común para explicar el nacimiento de obligaciones entre dos sujetos distintos.

En este punto, además, debemos añadir que desde las instituciones europeas tampoco se ha ofrecido una definición general del concepto contrato en el ámbito administrativo. Sin embargo, el TJUE cuando se ha referido a esta institución lo ha hecho también de una forma muy amplia, definiéndolo como "cualquier convenio entre dos personas diferentes" ${ }^{\prime \prime}$. Por lo tanto, entendiendo la institución contractual como la prestación voluntaria de un consentimiento entre dos personas diferenciadas, dirigida al establecimiento de una relación jurídica entre ellas.

Desde esta perspectiva amplia, nuevamente debemos formularnos otra pregunta: ¿puede un convenio administrativo configurarse como un contrato? Para responder este interrogante debemos partir de los requisitos que el artículo 1261 CC exige para poder hablar de la existencia de un contrato: esto es, que concurran un acuerdo de voluntades entre dos personas distintas, un objeto cierto y una causa.

\subsection{Los convenios interadministrativos como un acuerdo de voluntades de carácter bilateral}

En nuestra opinión, la conceptualización de los convenios entre entidades públicas como un acuerdo de voluntades de carácter bilateral y voluntario

8 En este sentido, por ejemplo, la STJUE de 18 de noviembre de 1999, asunto C-107/98, Teckal Srl., o la STJUE de 11 de mayo de 2006, asunto C-340/04, Carbotermo SpA. 
no resultaría excesivamente problemática. En efecto, desde un punto de vista formal, en los convenios interadministrativos nos encontraríamos ante un negocio jurídico celebrado entre dos personas jurídicas distintas, con plena capacidad de obrar, que libremente convienen la realización de determinadas prestaciones.

Por lo demás, tampoco podría ponerse en cuestión la propia voluntariedad del convenio, por cuanto el consentimiento de las partes no sólo tiene valor constitutivo de la relación obligatoria (art. 48.8 LRJSP) sino que, además, se nos presenta como totalmente autónomo respecto del consentimiento de la otra parte. En este sentido, no podemos olvidar que en el caso de los convenios entre administraciones públicas territoriales la autonomía para la gestión de sus respectivos intereses que nuestro ordenamiento jurídico reconoce a los diferentes niveles de gobierno y administración en los que se organiza territorialmente nuestro Estado (art. $137 \mathrm{CE}$ ) implica situar a las partes intervinientes en una posición jurídica de igualdad.

De ahí que, desde un punto de vista abstracto, los convenios interadministrativos no puedan considerarse como un mero acto unilateral de imposición de la voluntad de una administración pública sobre otra, ni tampoco como una sucesión de actos unilaterales propios de cada uno de los sujetos públicos que intervienen. Más bien al contrario, por cuanto, a pesar de que es cierto que la actuación de las administraciones públicas se encuentra siempre supeditada tanto al ordenamiento jurídico como a la satisfacción de los intereses generales (art. 103.1 CE), la libertad decisoria de las entidades públicas intervinientes jugaría un papel decisivo y regulador del contenido del convenio, proyectándose hacia una doble vertiente, esto es, para decidir libremente, en primer lugar, la formalización de dicha relación jurídica -por cuanto, para el cumplimiento de las tareas que tienen asignadas, las administraciones podrían acudir a cualquiera de los otros medios jurídicos que el ordenamiento pone a su disposición-y, en segundo lugar, la determinación de su contenido concreto9 ${ }^{9}$. De este modo podemos afirmar que, efectivamente, la concurrencia de dos voluntades diferenciadas se nos presentaría como un elemento esencial del régimen jurídico de los convenios.

\subsection{El objeto contractual}

El segundo elemento al que debemos hacer referencia para poder hablar de la existencia de un contrato es el relativo a su objeto, es decir, al sector de

9 En este punto, como se ha puesto de relieve muy acertadamente (BUSTILLO BOLADO, 2004, pp. 84-85), no debe confundirse la voluntariedad de la relación jurídica con la existencia de una negociación real entre las partes. Y es que, aunque la negociación puede ser prueba de la autonomía decisoria de los contratantes, no es un requisito indispensable para afirmar su existencia. 
la realidad social sobre el que recae el consentimiento de las partes. Como señala el Código Civil, en todo contrato las partes consienten en obligarse a dar alguna cosa o prestar algún servicio (art. 1251 CC). Por lo que, junto con el consentimiento y la causa, el objeto se convierte en uno de los requisitos indispensables de todo negocio jurídico contractual.

En este sentido, es evidente que el acuerdo de voluntades que supone un convenio administrativo se produce también para la realización de un objeto concreto y determinado. En efecto, mediante el convenio las partes se comprometen recíprocamente a la realización de una serie de prestaciones, la determinación de las cuales constituye el ámbito objetivo de la relación jurídica ${ }^{10}$.

En muchas ocasiones dichas prestaciones pueden no revestir un verdadero carácter contractual, por cuanto pueden integrar contenidos que quedan fuera del ámbito contractual. Sería el caso, por ejemplo, de los llamados convenios de competencias, a través de los cuales las partes pretenden incidir en el sistema de distribución de competencias entre las diversas organizaciones jurídicopúblicas; los convenios normativos, por los cuales las partes pactan el texto de una determinada norma y se comprometen a adoptarla en su respectivo ordenamiento interno, o los convenios para la creación de órganos u organizaciones mixtas ${ }^{11}$. Sin embargo, en otros muchos supuestos el objeto de los convenios entre administraciones públicas sí que puede llegar a confundirse fácilmente con la descripción de los diferentes tipos contractuales previstos actualmente en el TRLCSP.

Por ejemplo, ello es especialmente frecuente en los convenios de colaboración mediante los cuales una entidad pública realiza una determinada actuación positiva en favor de otra. En estos casos se articularía una suerte de relación prestación-contraprestación sobre una actividad -susceptible de poseer contenido económico- que se asemejaría mucho a las relaciones contractuales privadas. Más si tenemos en cuenta que, como ha señalado la doctrina (p. ej., Ávila Orive, 2002, pp. 95-102), la gama de prestaciones que las empresas privadas o los particulares pueden llevar a cabo es cada vez más extensa, pudiendo abarcar la gran mayoría de actividades que hoy en día desarrolla la Administración Pública.

No obstante, en este punto la nueva Ley de Régimen Jurídico del Sector Público introduce una novedad importante, si bien no exenta de dudas interpretativas. Así, el artículo 47.1 LRJSP, in fine, prevé que "los convenios no

10 De hecho, el artículo 49 c) LRJSP, al fijar el contenido mínimo de los convenios administrativos, prevé que, entre otros aspectos, estos deban incluir necesariamente el objeto del convenio y las actuaciones a realizar por cada sujeto para su cumplimiento.

11 En el ámbito doctrinal se han planteado numerosas clasificaciones de los convenios administrativos en atención a su objeto. Sirvan como muestra las previstas en PASCUAL GarCía (2012, pp. 43-46), Rodríguez de SAntiago (1997, pp. 143-331), Martín Huerta (2000, pp. 121-179) o GONZÁlEZ-ANTÓN ÁlvareZ (2002, pp. 131-175). 
podrán tener por objeto prestaciones propias de los contratos. En tal caso, su naturaleza y régimen jurídico se ajustará a lo previsto en la legislación de contratos del sector público".

¿Significa esto que, a partir de ahora, debemos considerar nulos todos aquellos convenios administrativos que tengan contenido contractual? A primera vista podría pensarse que sí. Más cuando, como avanzábamos anteriormente, el artículo 50.1 LRJSP prevé que la tramitación de los convenios deba acompañarse de una memoria en la que no sólo debe justificarse su necesidad y oportunidad, sino también "el carácter no contractual de la actividad en cuestión".

Sin embargo, no creo que esta sea la interpretación más adecuada, por cuanto debemos tener presente que el ámbito de aplicación objetivo de la normativa contractual española es tan amplio que, en la práctica, ello supondría una limitación muy notable a las posibilidades de colaboración entre los diferentes niveles de gobierno y administración.

Para hacernos una idea de dicha amplitud, basta con tomar en consideración la definición del contrato de servicios prevista en el artículo 10 TRLCSP, según la cual este tipo contractual comprende "cualquier prestación de hacer consistente en el desarrollo de una actividad que tenga un resultado distinto a la realización de una obra o la prestación de un suministro". Desde esta perspectiva podríamos preguntarnos: ¿qué clase de actividades administrativas no resultarían susceptibles de ser subsumidas, siquiera residualmente, dentro de esta categoría contractual?

Igualmente, si acudimos al Anexo II del TRLCSP veremos que este precepto concreta algunos de los supuestos que se incluyen dentro del concepto servicios a efectos del artículo 10 TRLCSP, haciendo referencia, entre otros muchos, a la prestación de servicios jurídicos, de investigación y desarrollo, servicios de contabilidad, auditoría y teneduría de libros, servicios editoriales y de imprenta, servicios de transporte, servicios de educación y formación profesional, servicios de limpieza, servicios de mantenimiento y reparación, servicios de telecomunicaciones, servicios de informática, servicios de estudio y encuestas o servicios sociales y salud. Nuevamente, a tenor de este extenso listado, podríamos cuestionarnos: ¿qué clase de actividades no resultarían capaces de ser calificadas, de algún modo, como contractuales?

Por lo tanto, creemos que, en realidad, el artículo 47.1 LRJSP no pretende establecer una prohibición en cuanto al objeto de los convenios administrativos sino diferenciar un doble régimen jurídico en función de este elemento: así, por un lado, encontraríamos los convenios cuyo objeto sea no contractual, que se regirán esencialmente por lo previsto en la LRJSP; $;$, por otro, encontraríamos los convenios que tengan un objeto contractual -este sería el sentido del último apartado del artículo 47.1 LRJSP al decir "en tal caso", esto es, cuando los convenios tengan por objeto prestaciones propias de los contratos-, los cuales deberán sujetar su régimen jurídico a lo previsto en la legislación de contratos del sector público. 
La justificación de dicha interpretación vendría dada por el hecho de que, cuando los convenios tengan por objeto una prestación propia de un contrato, no puede negarse a priori su consideración como un verdadero contrato público -entendido este, como veíamos anteriormente, en un sentido amplio-. En consecuencia, su régimen jurídico quedaría atraído necesariamente hacia lo previsto en la legislación básica en materia contractual.

\subsection{La causa contractual}

Finalmente, para poder hablar de la existencia de un contrato el artículo 1261 CC exige un último elemento: la causa contractual. A pesar de que la causa del contrato es una de las instituciones más complejas y controvertidas del derecho civil, podemos afirmar que con esta denominación haríamos referencia al fundamento jurídico que justifica la producción de las obligaciones que nacen del contrato. Así, todo negocio jurídico requiere de una causa o razón suficiente que ampare su tutela por parte del ordenamiento jurídico y le imprima su carácter vinculante.

En el caso que estamos examinando, creemos que no habría ningún obstáculo para extender la aplicación de este esquema contractual a la figura de los convenios administrativos. En su condición de acuerdo de voluntades sobre un objeto concreto podríamos entender también que este exige la existencia de un nexo causal entre las obligaciones que asume cada una de las partes. En efecto, todo convenio debe responder a una determinada finalidad jurídica que fundamente la posición que se atribuye a cada uno de los sujetos intervinientes.

En este sentido, si concretamos un poco más estas ideas generales, podemos ver cómo los convenios administrativos tendrían una causa específica (o causa inmediata) que coincidiría con el propósito concreto que persiguen las partes con su celebración. Es decir, con el resultado típico que pretende conseguirse mediante la formalización de dicho acuerdo. Sin embargo, como apuntábamos anteriormente, junto con esta finalidad específica, los convenios administrativos tendrían también una causa genérica (o causa mediata), vinculada a la idea de colaboración para la consecución de un fin común a las partes intervinientes. Y es que, como prevé expresamente el artículo 47.1 LRJSP, dichos acuerdos no deben verse solamente como un modo de proveer una determinada entidad de una actividad o servicio del que carece, sino que, desde un punto de vista abstracto, se nos presentan también como un instrumento de colaboración administrativa. Por consiguiente deberían poder justificarse en la voluntad de alcanzar de la manera más eficaz posible unos fines de interés general comunes a las partes intervinientes ${ }^{12}$.

12 En términos similares se han referido también a la causa de los convenios interadministrativos como un elemento definitorio de este tipo de negocios jurídicos, entre otros, SANTIAGo Iglesias (2014, pp. 924-925) y Pascual García (2014, pp. 37-43). 
Ha sido precisamente a partir de esta ineludible finalidad colaborativa que algunos autores (p. ej., Morell Ocaña, 1998, pp. 265-267) han venido a cuestionar el nexo causal de los convenios administrativos. En estos supuestos se parte de la idea de que una de las características esenciales de todo negocio jurídico contractual sería la de ordenar situaciones jurídicas presididas por una contraposición de intereses. De manera que deberían excluirse de tal calificativo todos aquellos supuestos -como el que estamos examinando- en que los intereses en juego no son contrapuestos sino paralelos.

No obstante, no podemos compartir dicha opinión, por dos razones fundamentales. En primer lugar, por cuanto entendemos que la contraposición de intereses no es un elemento determinante para la existencia de un contrato (ex art. $1254 \mathrm{CC}$ ). En efecto, la existencia de posiciones contrapuestas puede ser un elemento común a los contratos de intercambio, pero no es ni un requisito esencial a todo contrato, ni el único nexo causal previsto en nuestro ordenamiento. Al contrario, la colaboración entre las partes para la consecución de un objetivo común constituye también un vínculo contractual lícito y plenamente admitido por nuestro ordenamiento jurídico ${ }^{13}$.

Desde esta perspectiva podríamos entender que aquello determinante para hablar de un contrato es la presencia de intereses "distintos" -que es lo que genera la existencia de diferentes situaciones jurídicas (las partes) en una relación obligatoria-, pero sin que sea necesario que estos sean, al mismo tiempo, contrapuestos.

Pero es que, además, podríamos preguntarnos también si resultaría posible desligar cualquier actuación contractual de la voluntad de colaboración entre las partes. Y es que, como se advirtió tempranamente por la doctrina administrativista (Entrena Cuesta, 1957, p. 65), a pesar de los intereses privativos que pueden perseguir las partes, no es menos cierto también que un componente de colaboración se encuentra siempre presente o implícito en toda actuación contractual.

Por todo ello, creemos que los convenios interadministrativos responderían también al esquema causal propio de los negocios jurídicos contractuales. Y es que, aunque es cierto que su formalización pivota sobre la base de la consecución de unos intereses compartidos -un "fin común" (art. 47.1 LRJSP)-, también lo es que estos se nos presentan como un acuerdo de voluntades generador de verdaderas obligaciones recíprocas -concretas y exigibles (art. 47.1 LRJSP)-, en virtud de las cuales las partes asumen posiciones jurídicas distintas a las que tenían con anterioridad a la celebración de dicho acuerdo. En definitiva, como un negocio jurídico bilateral dirigido a la creación de obligaciones para las partes.

13 De ahí que, por ejemplo, en el ámbito privado se regulen figuras como el contrato de mandato (art. 1709 CC) que se define por la doctrina civil como un supuesto de cooperación jurídica; o como los contratos asociativos previstos en los artículo 1665 y siguientes CC, dirigidos a la consecución de fines comunes entre los diferentes socios. 


\section{El CARÁCTER ONEROSO DE LA RELACIÓN CONTRACTUAL}

En segundo lugar, el artículo 2.1 TRLCSP limita su ámbito de aplicación únicamente a los contratos que tengan carácter oneroso. Como en el caso anterior, el TRLCSP no nos define expresamente qué debemos entender como tales, sino que remite a las categorías tradicionales de nuestro derecho de las obligaciones y contratos. En este sentido, podemos entender que los contratos onerosos son aquellos en los que se produce un sacrificio económico para las dos partes contratantes -en oposición a los contratos gratuitos, en los que una de las partes se compromete a proporcionar a la otra una ventaja pero sin recibir ningún equivalente económico, es decir, con ausencia de una contraprestación- ${ }^{14}$. Esta diferenciación conceptual, por lo tanto, toma su punto de referencia en la naturaleza esencialmente patrimonial del contrato, valorando la posición jurídica de cada una de las partes para determinar si, efectivamente, existe un intercambio de prestaciones entre ellas.

Esta configuración tradicional de lo que debe entenderse por onerosidad de las relaciones contractuales es también la que se ha mantenido en el ámbito de la normativa europea sobre contratación pública. En este sentido, el TJUE - p. ej., en la Sentencia de 12 de julio de 2001, asunto C-399/98, Ordine degli Architetti delle province di Milano e Lodi- afirma que el carácter oneroso de un contrato público se refiere a la prestación que ofrece el contratista para la realización del objeto del contrato (FJ 77). O, más recientemente, en la Sentencia de 25 de marzo de 2010, asunto C-451/08, Helmut Müller GbmH, el Tribunal ha considerado que, para que pueda hablarse de la existencia de un contrato público, es necesario que el poder adjudicador reciba una prestación a cambio de una contraprestación (FJ 45).

Desde esta perspectiva, si aplicamos estos razonamientos al supuesto que nos ocupa, podremos comprobar cómo en muchos supuestos -sobre todo en aquellos en los que el convenio supone la prestación de una asistencia activa de una administración pública sobre otra- estos pueden configurarse como un negocio jurídico de carácter oneroso, ya que cada una de las partes de la relación asume un sacrificio patrimonial propio que, como decíamos anteriormente, se explica y justifica en atención a la contraprestación que recibe de la otra parte.

En este punto, además, hay que recordar que el carácter oneroso que se exige a la institución contractual no debe confundirse con la existencia de una finalidad de lucro para las partes contratantes. Como ha puesto de relieve el TJUE - p. ej., en la Sentencia de 23 de diciembre de 2009, asunto C-305/08, Consorzio Nazionale Interuniversitario per le Scienze-, bajo el concepto de operador económico utilizado por las directivas europeas pueden incluirse organismos

14 Son muchas las clasificaciones de los contratos que se han formulado por parte de la doctrina. En este sentido, entre muchas otras, podemos remitirnos a las de SANTOS BRIZ (2003, pp. 296-301) o DíEZ-PiCAZO y GuLLÓn (2012, pp. 23-29). 
cuya finalidad principal no sea la obtención de un lucro, ni tan siquiera la actuación en el mercado, como pueden ser las universidades o los centros de investigación (FJ 30). Al mismo tiempo, como se ha destacado en la Sentencia del TJUE de 19 de diciembre de 2012, asunto C-159/11, Azienda Sanitaria Locale di Lecce, Università del Salento, el contrato no perdería tampoco su carácter oneroso por el simple hecho de que este no sea lucrativo y su retribución se limite solamente al reembolso de los gastos realmente soportados por la realización de la prestación acordada (FJ 29).

Por lo tanto, lo único que se exige para someter un determinado negocio jurídico a la legislación contractual es simplemente que este pueda calificarse como oneroso pero sin que se requiera, además, que las partes que lo celebren lo hagan también con el ánimo subjetivo de obtener un enriquecimiento económico. Y así lo ha entendido también el ordenamiento jurídico español cuando, por ejemplo, en el artículo 54.1 TRLCSP admite con total normalidad que puedan ser contratistas de la Administración Pública, no sólo los empresarios mercantiles, sino también entidades que no tienen ánimo de lucro (como las organizaciones no gubernamentales, las fundaciones o, como veremos a continuación, también las propias administraciones públicas).

\section{El REQUisito SUbJeTIVO: LAS ENTIDADES DEL SECTOR PúBLICO}

Por último, el TRLCSP sólo califica como contratos del sector público aquellos que hayan sido celebrados por los entes, entidades y organismos comprendidos dentro de su ámbito subjetivo de aplicación (art. 2.1 TRLCSP). Por lo que la participación como adjudicador del contrato de una entidad que pertenezca al sector público se configura como una condición sine qua non para poder hablar de la existencia de un contrato público a efectos del TRLCSP.

En el caso de los convenios entre administraciones públicas que estamos comentando es evidente que nos encontramos ante sujetos que entran plenamente dentro del ámbito subjetivo de aplicación de la ley. En efecto, el TRLCSP prevé su plena aplicación, entre otros, a la Administración General del Estado, las Administraciones de las Comunidades Autónomas y las entidades que integran la Administración Local -art. 3.1 a) LCSP-. Por lo que podemos afirmar la plena coincidencia entre los sujetos que pueden formalizar estos convenios administrativos y la enumeración de los sujetos que pueden configurarse como parte activa en los contratos públicos regulados por el TRLCSP.

Ahora bien, cel hecho de que el sujeto pasivo de esta relación convencional sea también una entidad del sector público puede afectar a su consideración como contrato? A nuestro entender, no. A pesar de que, obviamente, el TRLCSP ha regulado la posición del contratista de la Administración Pública pensando principalmente en la figura del empresario mercantil, hoy en día se admite con normalidad que esta condición puedan asumirla todas aquellas personas 
-tanto públicas como privadas- que puedan actuar como parte, ofreciendo la realización de obras, el suministro de productos o servicios ${ }^{15}$.

De hecho, las propias directivas europeas en materia de contratación pública así lo prevén expresamente cuando, por ejemplo, en el artículo 2.8 de la nueva Directiva 2014/24/UE, de 26 de febrero, sobre contratación pública, se considera como posible contratista (operador económico) "toda persona física o jurídica, entidad pública o agrupación de tales personas o entidades". Al mismo tiempo, esta conclusión ha sido plenamente compartida por el TJUE cuando -p. ej., y entre otras muchas, en la citada Sentencia de 18 de noviembre de 1999, asunto C-107/99, Teckal Srl-- afirma: "la Directiva 93/63 es aplicable cuando una entidad adjudicadora, como un ente territorial, proyecta celebrar por escrito, con una entidad formalmente distinta de ella [... un contrato a título oneroso [...] independientemente de que dicha entidad sea o no, en sí misma, una entidad adjudicadora" (FJ 51). O, más recientemente, en la STJUE de 18 de diciembre de 2014, asunto C-568/13, Azienda Ospedaliero-Universitaria di Careggi-Firenze, se subraya el hecho de que cualquier entidad que se considere apta para garantizar la ejecución de un contrato público tiene derecho a participar en el mismo, con independencia de que su estatuto jurídico sea público o privado, o de si opera sistemáticamente en el mercado o si sólo interviene de manera ocasional (FJ 35).

\section{RECAPITULACIÓN}

Una vez analizados los diferentes elementos que configuran la noción de contrato público a efectos del TRLCSP podemos llegar a la conclusión de que, efectivamente, algunos de los convenios que pueden suscribirse entre administraciones públicas territoriales pueden encajar en su definición, en cuanto se nos presentan como acuerdos de voluntades de carácter bilateral y oneroso sobre un objeto de naturaleza contractual, celebrados por una entidad que forma parte del sector público.

Por lo que, llegados a este punto, se nos plantea una nueva pregunta: ¿cuál es la regulación concreta que el TRLCSP prevé para estos supuestos? En otras palabras, ¿el hecho de que estos convenios puedan considerarse como un contrato público significa, necesariamente, que su preparación y adjudicación se someterán siempre a los procedimientos de licitación y exigencias previstos en el TRLCSP?

15 En el mismo sentido se expresan, entre otros, Gosálbez PeQueÑo (2000, p. 120) o RoDRíGUEZ DE SANTIAGO (1997, pp. 364-366). 


\section{EL TRATAMIENTO DE LOS CONVENIOS ENTRE ADMINISTRACIONES PÚBLICAS TERRITORIALES A EFECTOS DEL TRLCSP}

Para responder las preguntas anteriores debemos partir de una premisa muy importante: a pesar de que el TRLCSP se aplica generalmente a todos los contratos onerosos y celebrados por escrito por los sujetos pertenecientes al sector público (art. 2.1 TRLCSP), hay determinadas relaciones jurídicas que -aunque pudieran definirse teóricamente como contratos públicos a efectos de la legislación contractual- quedan ex lege fuera de su ámbito de aplicación (art. 4.1 TRLCSP). Por lo tanto, no todas las relaciones contractuales formalizadas por entidades pertenecientes al sector público quedan automáticamente sujetas al TRLCSP, sino que podemos encontrar un conjunto heterogéneo de figuras que, por motivos diversos y por propia decisión del legislador, quedan fuera del ámbito de aplicación de dicha norma ${ }^{16}$.

Es precisamente en este ámbito en el que debemos centrarnos ahora, para analizar si resultaría posible incluir los convenios entre administraciones públicas que estamos analizando en alguna de las excepciones previstas por el TRLCSP. Y es que, en caso de que fuera posible esta identificación -e, insistimos, a pesar de que pudiéramos considerar formalmente estos convenios como un acuerdo de carácter contractual-, su régimen jurídico quedaría al margen de la aplicación de las reglas de la contratación pública.

En este sentido, si partimos del listado de contratos y negocios excluidos previsto en el mencionado artículo 4.1 TRLCSP, a nosotros nos interesa especialmente examinar la posible concurrencia de dos de ellos: en primer lugar, los encargos efectuados a entidades que reúnan la condición de medio propio o servicio técnico de la Administración - art. 4.1 n) TRLCSP-y, en segundo lugar, la exclusión relativa a los convenios de colaboración entre administraciones públicas -art. 4.1 c) TRLCSP-.

\section{LA UTILIZACIÓN DE MEDIOS PROPIOS POR PARTE DE LA ADMINISTRACIÓN}

La primera excepción a la que tenemos que hacer referencia es la relativa a la utilización de medios propios por parte de la Administración. Con esta

16 Por lo que se refiere a dichas exclusiones, en algunos casos se trata de supuestos no regulados directamente por las directivas europeas -como los contratos relativos a servicios de arbitraje o conciliación [art. 4.1 k) TRLCSP] -; en otros, su justificación hay que buscarla en la especialidad de las relaciones contractuales que se establecen, que aconseja su remisión a una normativa más específica -como los contratos regulados por la normativa laboral [art. 4.1 a) TRLCSP]-. Incluso, como ha puesto de relieve la doctrina, dentro del listado exhaustivo del artículo 4.1 TRLCSP se englobarían supuestos que difícilmente podrían ser calificados como verdaderos contratos públicos pues carecen de algunos de los requisitos que califican como tales dichos negocios jurídicos (Gimeno Feliú, 2010, pp. 43-46). 
denominación genérica ${ }^{17}$ se pretende hacer referencia a aquellos supuestos en los que una determinada administración pública a la hora de gestionar sus competencias decide acudir directamente a sus propios medios materiales (ya tengan estos personalidad jurídica propia o no), sin necesidad de recurrir contractualmente a ninguna entidad ajena a su propia organización ni cooperar con otras entidades públicas.

Se refiere, por tanto, a una forma de actuación de la Administración Pública cuya importancia reside en el hecho de que se formaliza de modo directo, esto es, al margen de los procedimientos competitivos de adjudicación de los contratos públicos previstos en la normativa contractual. Y es que cuando hablamos de supuestos de auto-provisión nos referimos a relaciones puramente internas de la Administración -de auto-provisión-, que se producen en el seno de una misma organización administrativa y que, en consecuencia, no dan lugar al nacimiento de un verdadero contrato público entre dos personas jurídicamente diferenciadas.

El TJUE se ha referido a este tipo de relaciones en muchas ocasiones afirmando -p. ej., en la Sentencia de 11 de enero de 2005, asunto C-26/03, Stadt Halleque las directivas europeas sobre contratación no impiden que una autoridad pública pueda realizar las tareas de interés público que le correspondan con sus propios medios administrativos, técnicos y de cualquier otro tipo, sin verse obligada a recurrir a entidades externas y ajenas a sus servicios. Añadiendo que, en estos supuestos, no existiría un contrato a título oneroso celebrado con una entidad jurídicamente distinta de la entidad adjudicadora y, por tanto, no habría que aplicar las normas europeas sobre contratación (FJ 48).

En estos supuestos, y aunque desde un punto de vista meramente formal pudiéramos encontrarnos ante un acuerdo entre dos personas jurídicas diferenciadas, lo cierto es que materialmente no es posible hablar en realidad de la existencia de un negocio jurídico de carácter bilateral. Y es que se entiende que el recurso a personificaciones instrumentales no sería más que una manifestación del principio de auto-organización de las administraciones públicas, pero sin que esta personalidad diferenciada implique, en ningún caso, la desvinculación de dicha entidad instrumental de la administración pública de la que trae causa ${ }^{18}$.

17 En este punto debemos advertir que la denominación de este fenómeno no resulta pacífica para la doctrina administrativista española, que ha utilizado muchas y variadas formas para referirse a esta figura: desde contratos domésticos hasta contratos internos, pasando por encargos de ejecución o encomiendas de gestión. En alguna ocasión hemos preferido optar por denominarlos contratos de auto-provisión, no sólo por cuanto responde fielmente a su denominación original en inglés - "in-bouse providing contracts"- sino porque además, como veremos a continuación, creemos que expresa de forma gráfica y acertada su concepto. En este sentido, Vilalta Reixach (2014, p. 943).

18 Sobre los encargos a medios propios es mucha la bibliografía existente. En este sentido, 
Ahora bien, una vez admitida genéricamente la posibilidad de que la Administración Pública pueda valerse de sus propios recursos materiales para el cumplimiento de sus tareas de interés público se nos plantea otra duda igualmente importante: ¿cuáles son los criterios que permiten considerar que la Administración actúa "a través de sus propios medios"? Y, en lo que se refiere a nuestro concreto objeto de estudio, ¿sería posible considerar un convenio entre dos administraciones públicas territoriales como una relación de carácter meramente interno y, por lo tanto, ajena al ámbito contractual?

Para responder a esta cuestión debemos hacer referencia a la importante Sentencia de 18 de noviembre de 1999, asunto C-107/99, Teckal Srl., en la que el Tribunal de Justicia de la Unión Europea se ocupó de precisar en qué supuestos podemos entender que nos encontramos en una relación de autoprovisión. En este caso, el TJUE empieza su argumentación recordando que existe un contrato público a efectos de la normativa contractual siempre que nos encontramos ante un contrato oneroso celebrado por escrito entre un poder adjudicador y otra persona jurídica diferenciada, ${ }_{i}$ pero añade $-y$ aquí reside la principal novedad- que no es suficiente con este acuerdo bilateral sino que, además, es necesario que las relaciones entre los poderes adjudicadores y los operadores económicos se rijan por un principio de autonomía efectivo y no meramente formal.

Por lo tanto, como apuntábamos anteriormente, para el TJUE el requisito de la personalidad jurídica propia de los sujetos contratantes no constituye un elemento determinante para hablar de la existencia de un contrato público, sino que será la existencia de una voluntad decisoria propia la que nos permitirá calificar estas relaciones jurídicas como contractuales. En este sentido, el TJUE en la citada Sentencia Teckal nos dice que la presunción de la existencia de un contrato entre una determinada administración pública y otra entidad jurídicamente diferenciada quedará desvirtuada siempre que, a "la vez, el ente territorial ejerza sobre la persona de que se trate un control análogo al que ejerce sobre sus propios servicios y esta persona realice la parte esencial de su actividad con el ente o los entes que la controlan" (FJ 50).

Este planteamiento jurisprudencial no solo ha sido posteriormente reafirmado en muchas otras sentencias del TJUE ${ }^{19}$, sino que también ha sido positivizado de forma expresa por nuestro ordenamiento jurídico. Así, el artículo $4.1 \mathrm{n})$ TRLCSP excluye de su ámbito de aplicación los negocios en virtud de los cuales se encargue la realización de una determinada prestación a una entidad que tenga atribuida la consideración de medio propio o servicio técnico; toda

entre otros, podemos citar: Pernás García (2012, pp. 59-175), Bernal Blay (2006, pp. 77-90), Pascual García (2010, pp. 33-52) o Vilalta Reixach (2014, pp. 941-990).

19 Podemos citar, entre otras muchas, la STJUE de 13 de diciembre de 2008, asunto C-324/07, Coditel Brabant S.A., la STJuE de 13 de junio de 2013, asunto C-386/11, Piepenbrock Diensleistungen GmbH, o la STJUE de 19 de junio de 2014, asunto C-574/12, Centro Hospitalar de Setúbal. 
vez que, a partir de las consideraciones realizadas por el TJUE, el TRLCSP fija también los criterios por los cuales los diferentes entes, entidades y organismos del sector público español pueden ser considerados como medios propios de la Administración (art. 24.6 TRLCSP) ${ }^{20}$.

No podemos entrar ahora a analizar con mayor detalle el régimen jurídico de estas relaciones de auto-provisión ${ }^{21}$, pero sí que nos interesa destacar que muy difícilmente podríamos incluir los convenios entre administraciones públicas territoriales dentro de esta categoría, por cuanto resulta ciertamente difícil poder extender la consideración de medio propio o servicio técnico de la Administración $-\mathrm{y}$, por tanto, negar la condición de tercero de la entidad que recibe el encargo- en aquellos supuestos en que dos administraciones públicas territoriales diferenciadas convienen la realización de una determinada prestación de carácter material o de servicios.

En efecto, en estos casos no estaríamos ante una mera proyección instrumental de una misma organización administrativa sino ante una relación jurídica entre dos sujetos públicos diferentes, portadores de unos intereses propios y con plena capacidad para actuar autónomamente sus decisiones, sin ningún tipo de dependencia o subordinación jerárquica entre ellos. De esta manera, no podríamos afirmar la existencia entre ellas de un control análogo al que ejerce sobre sus propios servicios; elemento que, de acuerdo con el TJuE y el artículo 24.6 TRLCSP, es indispensable para poder hablar de medios propios o servicios técnicos de la Administración ${ }^{22}$.

Por otro lado, en el caso de los convenios administrativos entre dos administraciones públicas territoriales tampoco se cumpliría el segundo de los requisitos previstos por la jurisprudencia del TJUE y por el artículo 24.6 TRLCSP: la realización de la parte esencial de la actividad con la entidad que controla el medio propio ${ }^{23}$. Y es que, como venimos insistiendo, en estos casos nos

20 A todo esto, hay que tener presente que el artículo 12.1 de la nueva Directiva 2014/24/ UE, de 26 de febrero, ha recogido también estos supuestos, excluyendo de su ámbito de aplicación los contratos adjudicados por un poder adjudicador a otra persona jurídica de derecho público o privado siempre que se cumplan todas y cada una de las condiciones siguientes: "a) que el poder adjudicador ejerza [...] un control análogo al que ejerce sobre sus propios servicios; b) que más del $80 \%$ de las actividades de esa persona se lleven a cabo en el ejercicio de los cometidos que le han sido confiados por el poder adjudicador que la controla $[\ldots]$, y c) que no exista participación directa de capital privado en la persona jurídica controlada...".

21 Como hacíamos anteriormente, podemos remitirnos, entre otros muchos, a PERNÁs GARCía (2012, in totum), Bernal Blay (2006, pp. 77-90), Pascual García (2010, pp. 33-52) o VilaLTA ReIXACH (2014, pp. 941-990).

22 Sobre el alcance y significado del requisito del control análogo pueden verse, entre otras, la STJUE de 11 de mayo de 2006, asunto C-340/04, Carbotermo Spa. (FJ 36) o la STJUE de 29 de noviembre de 2012, asuntos acumulados C-182/11 y C-183/11, Econord, Spa.

23 Por lo que se refiere al significado de dicho requisito, aunque ha sido objeto de menor atención por parte del TJUE, podemos citar, entre otras, la STJUE de 11 de mayo de 2006, 
encontraremos con dos entidades públicas a las que el ordenamiento jurídico asigna unas finalidades propias y específicas. Por lo que la realización de un determinado encargo material por parte de una de ellas no constituiría el objetivo principal de su actividad sino que se configuraría simplemente como un supuesto ocasional de colaboración interadministrativa.

Por lo tanto, al no cumplirse con dichos requisitos, no podríamos considerar que estamos ante una relación de carácter meramente interno entre una determinada organización administrativa y sus propios medios materiales; sino más bien al contrario. Nos encontraríamos ante una auténtica relación bilateral entre dos sujetos formal y materialmente diferenciados, por lo que no podríamos acudir a la exclusión prevista en el artículo 4.1 n) TRLCSP.

¿Esto supone automáticamente que los convenios entre administraciones públicas territoriales deben quedar sujetos, en todo caso, a las exigencias del TRLCSP? No necesariamente, porque, como adelantábamos con anterioridad, aún podríamos intentar justificar la no sujeción de estos negocios a la legislación contractual en atención a otra de las exclusiones previstas en el artículo 4.1 TRLCSP.

\section{LA EXCLUSIÓN DE LAS RELACIONES DE COLABORACIÓN ENTRE ADMINISTRACIONES PÚBLICAS}

Efectivamente, al margen de los llamados contratos de auto-provisión, a la hora de analizar el tratamiento contractual de los convenios interadministrativos podríamos plantearnos también la posible aplicación del artículo $4.1 \mathrm{c}$ ) TRLCSP. Dicho precepto excluye de su ámbito de aplicación los convenios de colaboración que celebre la Administración General del Estado con las entidades gestoras y servicios comunes de la Seguridad Social, las universidades públicas, las comunidades autónomas, las entidades locales, organismos autónomos y restantes entidades públicas, o los que celebran estos organismos y entidades entre sí, excepto que, por su naturaleza, tengan la consideración de contratos sujetos al TRLCSP.

Antes de entrar a examinar más detalladamente esta exclusión y su posible aplicación al supuesto que nos ocupa, debemos comenzar recordando una idea que, a pesar de ser obvia, en ocasiones parece pasar desapercibida. Y es que el TRLCSP no prevé una exclusión absoluta e incondicionada de su ámbito de aplicación de todas las relaciones convencionales entre entidades públicas sino solamente de aquellas que no tengan una naturaleza contractual -art. 4.1 c) TRLCSP-.

Ahora bien, es también cierto que, hecha esta constatación, la determinación de su significado y alcance resulta muy compleja, por cuanto, ca qué se refiere el TRLCSP cuando habla de la naturaleza contractual de un convenio? ¿Cuál 
es el elemento concreto que atribuye esta naturaleza a un determinado acuerdo entre entidades públicas? ¿Es su objeto? ¿Son las entidades que participan en la formalización de un determinado negocio jurídico? ¿Son las contraprestaciones pactadas entre las partes?

\subsection{Crítica a la regulación actual del TRLCSP}

En nuestra opinión, la redacción del TRLCSP en este punto es francamente criticable, ya que hacer depender la sujeción de los convenios de colaboración entre entidades públicas al TRLCSP de una noción tan indeterminada como es su "naturaleza jurídica" sólo contribuye a añadir más confusión a su régimen jurídico. Sobre todo si se tiene en cuenta que, ante la ausencia de una definición legal de esta figura, una de las cuestiones que más se habían venido discutiendo había sido, precisamente, la naturaleza jurídica de los convenios interadministrativos.

Una primera posible interpretación de este requisito podría consistir en entender que, con esta terminología, el TRLCSP pretende sujetar a sus prescripciones todos aquellos negocios jurídicos celebrados entre entidades jurídicopúblicas que, independientemente de su denominación, encajen dentro de la noción amplia de contrato que mencionábamos con anterioridad. Es decir, todo acuerdo de voluntades entre dos personas diferenciadas -independientemente de que esta sea también otra entidad pública- de carácter oneroso y cuyo objeto encaje con alguna de las prestaciones materiales previstas por el propio TRLCSP.

No obstante, si trasladamos estas consideraciones al ámbito de los convenios administrativos que estamos analizando rápidamente se nos ponen de relieve algunas de las dificultades a las que habíamos hecho ya referencia. Y es que, como mencionábamos, si no hay impedimento para poder considerar dichos negocios jurídicos como verdaderos contratos públicos a los efectos del TRLCSP, entonces menos dificultades habría para reconocerles también naturaleza contractual. Al mismo tiempo, teniendo en cuenta la notable amplitud del ámbito de aplicación material de la legislación contractual, podríamos llegar también con facilidad a la conclusión de que, en muchos supuestos, las actuaciones que actualmente son objeto de convenio entre administraciones públicas podrían ser susceptibles de encajar en alguno de los distintos tipos contractuales regulados por el TRLCSP.

En este sentido, si admitiéramos dicha interpretación amplia acerca de la naturaleza contractual de los convenios, deberíamos concluir afirmando la plena aplicabilidad a estos negocios jurídicos del régimen legal previsto en el TRLCSP. Las consecuencias que esto conllevaría para su régimen jurídico, como fácilmente puede imaginarse, serían de enorme trascendencia, hasta el punto de llevarnos a cuestionar la propia funcionalidad de esta institución. $Y$ es que se perderían algunos de los argumentos que, tradicionalmente, han justificado el recurso a esta figura: en particular, su flexibilidad e inmediatez. 
De esta manera, las entidades públicas territoriales que quisieran formalizar dichos convenios ya no dispondrían de plena libertad para elegir la forma de articular esta colaboración, sino que, para la preparación y adjudicación de estos acuerdos, deberían acudir inexcusablemente a los procedimientos competitivos de adjudicación previstos en la legislación contractual ${ }^{24}$. Así, la validez del convenio ya no dependería principalmente del acuerdo entre las dos partes interesadas (art. 48.8 LRJSP) sino que, además, sería requisito inexcusable la tramitación de un expediente de contratación (art. 109 TRLCSP) en el que, una vez finalizado el procedimiento correspondiente (art. 138.2 TRLCSP), se adjudicara el contrato a aquel contratista -fuera una administración pública o un particular- que hubiera presentado la oferta económicamente más ventajosa (art. 150 TRLCSP).

No obstante, creemos que es posible plantear una interpretación alternativa del TRLCSP, que nos permita también poner en valor la finalidad específica de colaboración entre administraciones públicas para la consecución de finalidades de interés público que caracterizaría la figura de los convenios $\mathrm{y}$, con ella, poder justificar su exclusión del ámbito de aplicación del TRLCSP. En este sentido, dedicaremos el último apartado de nuestra exposición a poner de relieve cómo, más allá de su posible configuración teórica como un contrato, el elemento causal de los convenios entre administraciones públicas puede configurarse como un elemento que nos puede llevar a modular su necesaria sujeción al TRLCSP.

\subsection{La colaboración administrativa como fundamento para la exclusión de los convenios administrativos del ámbito de aplicación del TRLCSP}

Como se ha apuntado en diferentes ocasiones, los convenios entre administraciones públicas encuentran su justificación en los principios constitucionales de eficacia y de colaboración administrativa (art. 103.1 CE), ya que tienen por finalidad dotar al conjunto del sistema administrativo de un instrumento con el que poder garantizar el correcto funcionamiento de la actuación pública y la consecución de las finalidades de interés general que se les encomiendan ${ }^{25}$.

24 BAÑo LEÓN, muy acertadamente, ha destacado también esta idea al afirmar que la irrupción de las directivas europeas ha marcado un antes y un después con respecto a la libertad que tenían los países miembros de utilizar unas u otras técnicas jurídicas. Así, aunque formalmente puedan seguir utilizándose distintas fórmulas, los procedimientos de preparación y adjudicación de aquellas actividades administrativas que puedan considerarse contratos irremediablemente tendrán que ajustarse a las reglas de publicidad, libre concurrencia y criterios de selección previstos por la normativa europea sobre contratación pública. Ver BAÑo LEÓN (2004, p. 18).

25 Se han referido a dichas finalidades, entre otros, SANTIAGO IGLESIAS (2014, p. 892) y MARTín HuERTA (2000, pp. 27-34). 
En este sentido, las obligaciones que se asumen a través de un convenio interadministrativo no se nos presentan sólo como una forma de intercambio patrimonial o como una manera de abastecerse de unos determinados recursos de los que no se dispone sino que, en realidad, se configuran como una manifestación de la capacidad organizativa y relacional del conjunto del sistema administrativo ${ }^{26}$. Es decir, como una forma de administrar el complejo organizativo público.

Aunque, efectivamente, en muchos casos este tipo de convenios presuponen una dualidad de sujetos que acuerdan entre sí la realización de una determinada prestación a cambio de una contraprestación -lo que, desde un punto de vista teórico, nos llevaba a afirmar la existencia de un contrato del sector público a efectos del TRLCSP-, tanto la naturaleza pública de las personas que intervienen en este negocio como, sobre todo, los fines de interés general que se persiguen por ambas partes son elementos que, necesariamente, caracterizan esta figura y que nos permitirán diferenciarlos de los simples contratos de subordinación entre las administraciones públicas y el resto de operadores económicos.

A nuestro entender, reconducir automáticamente las relaciones entre entidades públicas hacia los mismos planteamientos que rigen la gestión con los sujetos privados -olvidando que la maximización de los beneficios o la defensa de la libre competencia no son los únicos factores que deben ser valorados en analizar una actividad administrativa con trascendencia económica- resulta, como mínimo, discutible. Y es que, como decíamos, el fin último de los convenios entre administraciones públicas territoriales no respondería solamente a la satisfacción de las necesidades clientelares de una determinada administración pública, sino que -desligada de la idea de mercado y de cualquier finalidad lucrativa- nos aparece como una consecuencia lógica de una determinada forma de organización del Poder Público, que atribuye al conjunto de entidades públicas la responsabilidad por el cumplimiento de los fines de interés general. Y son, precisamente, estas específicas finalidades las que, a nuestro entender, determinarían la naturaleza jurídica de estos negocios a efectos del artículo $4.1 \mathrm{c}$ ) TRLCSP.

Esta interpretación de los convenios que se propone -que pone el énfasis en la finalidad colaborativa perseguida por las partes- encaja plenamente con la interpretación que, más recientemente, ha expresado también el TJuE en relación con la normativa europea sobre contratación pública. De hecho, ante

De hecho, esta institución nos permite poner en valor la idea de la Administración Pública como sistema. En efecto, partiendo de la constatación de que la Administración española no es más que una totalidad organizada, podemos llegar a la conclusión de que la capacidad para ordenar y gestionar sus respectivos intereses que les reconoce nuestro ordenamiento jurídico no se limita sólo a sus propios medios humanos y materiales, sino que incluye también su necesaria proyección exterior, su contenido relacional externo, mediante las relaciones de colaboración con otras entidades públicas. 
las muchas dudas que los Estados miembros de la UE habían planteado sobre el ámbito de aplicación de las directivas contractuales, el TJuE ha venido a cuestionar la aplicación general de las normas sobre contratación pública a los contratos celebrados entre entidades públicas.

En efecto, en la importante Sentencia de 29 de junio de 2009, asunto C-480/06, Comisión Europea/República Federal de Alemania, el TJUE constata que, a pesar de la existencia de un acuerdo contractual entre dos administraciones públicas -que, al no cumplir los requisitos exigidos por la STJUE Teckal, tampoco podía reconducirse a la existencia de un encargo sobre medios propios (o contrato de auto-provisión)-, estaríamos igualmente ante un supuesto que merecía ser excluido del ámbito de aplicación de la legislación contractual, ya que el negocio jurídico controvertido no se configuraba como un simple contrato público sino que venía a establecer una relación de cooperación entre entidades locales, que tenía como finalidad garantizar la realización de una misión de servicio público común a las entidades participantes (FJ 37).

Este contrato -añade el TJUE- debía analizarse, por tanto, como la culminación de una acción de colaboración interadministrativa que, en la medida que se regía únicamente por consideraciones de interés público, no cuestionaba los objetivos principales de la normativa europea sobre contratación pública (esto es, la libre circulación de servicios y su apertura a la competencia no falseada en todos los Estados miembros). En otras palabras, al configurarse como una relación de cooperación para el cumplimiento de una finalidad de interés general, se entiende que estos acuerdos van más allá del contenido propio de los contratos públicos y, consecuentemente, deberían quedar fuera del ámbito de aplicación de la legislación contractual.

A pesar de que el TJUE no ha entrado a desarrollar más detalladamente estos planteamientos, lo cierto es que esta argumentación se ha mantenido firme en sus resoluciones posteriores; así, por ejemplo, en la Sentencia de 22 de diciembre de 2010, asunto C-215/09, Mebiläinen Oy (FJ 31), en la Sentencia de 19 de diciembre de 2012, asunto C-159/11, Azienda Sanitaria Locale di Lecce, Università del Salento (FJ 34-35) o en la Sentencia de 13 de junio de 2013, asunto C-386/11, Piepenbrock Diensleistungen GmbH \& Co. Kg (FJ 34). De este modo, el TJUE parece dar un paso más en el reconocimiento de una mayor autonomía organizativa de los Estados miembros en el cumplimiento de sus responsabilidades de servicio público, admitiendo que -más allá de las operaciones de auto-provisión que mencionábamos anteriormente-, pueden existir también otras fórmulas de cooperación que queden fuera del ámbito de aplicación de la legislación contractual.

Al mismo tiempo debemos subrayar que estos razonamientos jurisprudenciales han sido plenamente asumidos por el resto de instituciones comunitarias, tanto la Comisión Europea como el Parlamento Europeo. Por lo que se refiere a la Comisión Europea, podemos destacar el "Libro Verde sobre la modernización de la política de contratación pública en la UE. Hacia un 
Mercado europeo de la contratación pública más eficiente" -Comunicación de la Comisión Europea COM (2011) 15, de 27 de enero-, en el que -si bien se parte de la consideración de que una competencia leal y abierta en el Mercado Interior impide que los contratos celebrados entre entidades públicas puedan quedar automáticamente excluidos del ámbito de aplicación de las directivas en materia de contratación pública- se admite, sin embargo, que esto no impide que, en algunos supuestos, la aplicación de las normas contractuales a determinadas formas de colaboración entre entidades públicas no resulte del todo conveniente.

En este sentido, en el mencionado Libro Verde, la Comisión Europea destaca que debería dibujarse una línea divisoria entre, por un lado, aquellos acuerdos entre poderes adjudicadores guiados exclusivamente por consideraciones de interés público -y que, por lo tanto, deben quedar al margen de la aplicación de la normativa contractual $-y$, por otro, aquellas otras actividades de contratación de bienes, obras o servicios que, a diferencia de los anteriores, sí han de someterse a la legislación contractual y beneficiarse de una competencia abierta entre todos los operadores económicos.

Posteriormente, la Comisión Europea tuvo nuevamente ocasión de desarrollar de una forma mucho más extensa todos estos planteamientos en el "Documento de trabajo de los servicios de la Comisión relativo a la aplicación de la normativa sobre contratación pública de la UE en las relaciones entre poderes adjudicadores, especialmente en la cooperación dentro del sector público" -SEC (2011) 1169, de 4 de octubre-. En este documento, de carácter orientativo y no vinculante, se insiste en la idea de que los diferentes poderes adjudicadores pueden establecer relaciones de colaboración horizontal entre sí, sin crear ningún medio propio conjunto, que conlleve la celebración de acuerdos no comprendidos dentro del ámbito de aplicación de la normativa sobre contratación pública de la UE.

No obstante, la admisión de estos acuerdos exigiría el cumplimiento de las siguientes circunstancias: que en la relación de colaboración intervengan sólo poderes adjudicadores y no haya participación de capital privado; que el acuerdo revista el carácter de una cooperación real con vistas al desarrollo de una tarea común y que se rija únicamente por consideraciones de interés público; excluyéndose, por tanto, las relaciones entre poderes públicos que tengan vocación de mercado ${ }^{27}$.

Pero más allá de poner de relieve este cambio de orientación interpretativa, nos interesa más destacar que las instituciones europeas han positivizado todas estas consideraciones, incorporándolas en la nueva Directiva 2014/24/ UE, de 26 de febrero, sobre contratación pública. Así, en el artículo 12.4 de

27 Véase el documento de trabajo de los servicios de la Comisión Europea relativo a la aplicación de la normativa sobre contratación pública de la UE en las relaciones entre poderes adjudicadores, SEC (2011) 1169, de 4 de octubre, p. 14. 
esta nueva directiva se excluyen de su ámbito de aplicación los contratos celebrados exclusivamente entre dos o más poderes adjudicadores,

... cuando se cumplan todas y cada una de las condiciones siguientes:

a) Que el contrato establezca o desarrolle una cooperación entre los poderes adjudicadores participantes con la finalidad de garantizar que los servicios públicos que les incumben se prestan de modo que se logren los objetivos que tienen en común $_{i}$

b) Que el desarrollo de dicha cooperación se guíe únicamente por consideraciones relacionadas con el interés público, y

c) Que los poderes adjudicadores participantes realicen en el mercado abierto menos del 20\% de las actividades objeto de la cooperación.

Por lo tanto, siempre que se cumplieran estrictamente los requisitos fijados, la nueva directiva permitiría que dos administraciones públicas (dos poderes adjudicadores, en la terminología comunitaria) pudieran acordar desarrollar en común las tareas de servicio público que tuvieran asignadas -aunque pudieran tener contenido contractual- sin que, para ello, tuvieran que acudir a los procedimientos de licitación previstos por la directivas europeas.

En este sentido, y sin perjuicio de que la legislación española en materia de contratos del sector público deberá necesariamente adaptarse a esta nueva realidad normativa europea ${ }^{28}$, creemos que, a día de hoy, todos estos argumentos podrían ayudarnos igualmente a reinterpretar el vigente artículo $4.1 \mathrm{c}$ ) TRLCSP. $Y$ es que, como decíamos anteriormente, el derecho español en esta materia sólo puede ser correctamente aplicado a la luz del ordenamiento europeo $;$ de modo que podríamos entender que, en la medida que pudiera probarse que los convenios entre administraciones públicas territoriales tienen como finalidad última el establecimiento de una relación de colaboración entre ellas, dirigida a la consecución de finalidades de interés general que van más allá de la lógica del mercado, podrían calificarse como un acuerdo de naturaleza no contractual. Y, por lo tanto, podrían excluirse del ámbito de aplicación del TRLCSP.

Este carácter no contractual y eminentemente colaborativo de los convenios interadministrativos podría fundamentarse no sólo en la lógica ausencia de vocación de mercado de las administraciones públicas participantes, sino

28 Según el artículo 90 de la Directiva 2014/24/UE, de 26 de febrero, el plazo de transposición de dicha normativa por parte de los Estados miembros terminaría el 18 de abril de 2016. En fecha 17 de abril de 2015 el Ministerio de Hacienda y Administraciones Públicas hizo público el Anteproyecto de Ley de Contratos del Sector Público que pretendía transponer al ordenamiento español la mencionada Directiva 2014/24/UE. Sin embargo, dicho Anteproyecto no ha llegado todavía a aprobarse. 
también en el hecho de que el elemento económico implícito en estos acuerdos tiene un carácter meramente accidental, en cuanto la actuación de los sujetos participantes no responde a pautas comerciales o mercantiles, ni a la obtención de un lucro, sino que debe obedecer obligatoriamente (ex art. 103.1 CE) a criterios de interés público ${ }^{29}$.

Y resulta especialmente importante destacar esta última idea por cuanto las instituciones comunitarias han hecho hincapié en la necesaria naturaleza no comercial que debe presidir las relaciones de colaboración entre entidades públicas; teniendo presente que los movimientos financieros entre las partes participantes en una determinada relación jurídica han sido uno de los aspectos que el TJUE ha tenido en cuenta a la hora de valorar la necesidad de someter o no un determinado negocio jurídico entre entidades públicas a la legislación contractual ${ }^{30}$.

En todo caso, obviamente, para poder excluir dicha relación convencional del ámbito de aplicación del TRLCSP deberíamos comprobar que con ellos no se formaliza un mero intercambio de prestaciones patrimoniales entre dos sujetos diferenciados sino que, en realidad, estamos ante una relación de cooperación dirigida al cumplimiento de fines de interés público compartidos por las diferentes entidades participantes. Y es que, precisamente, es el hecho de que se trate del cumplimiento de una misión común de servicio público lo que justifica que decidan emprender una solución conjunta ${ }^{31}$.

Al mismo tiempo, y desde un punto de vista subjetivo, la figura de los convenios a la que nos estamos refiriendo solamente se formalizaría entre administraciones públicas, cuya creación responde indudablemente a consideraciones de interés general. Por lo que, de nuevo, estaríamos asegurando también que

29 De hecho, se ha afirmado que el carácter no comercial implícito en los acuerdos de colaboración entre administraciones públicas supondría también admitir que habrá un menor interés por parte de los empresarios privados para participar en su ejecución, de modo que no podría producirse ninguna consecuencia negativa en el mercado como resultado de su adjudicación directa. Pedersen y Olsson (2010, p. 43).

30 Podemos citar, por ejemplo, la ya mencionada Sentencia de 29 de junio de 2009, Comisión Europea/República Federal de Alemania, en la que el TJuE entiende que la relación de colaboración que se establecía en dicho convenio no respondía al típico carácter contractual de pago de un precio por la prestación de unos servicios porque el acuerdo celebrado no daba lugar a más movimientos financieros que aquellos dirigidos a reembolsar los gastos realizados por la entidad pública adjudicataria (Fj 44).

31 En este punto, las conclusiones del Abogado General, Sr. Paolo Mengozzi, en el asunto C-15/13, Datenlotsen Informationssysteme GMBH/Technische Universität Hamburg-Harburg, de 23 de enero de 2014, se refirieron a este elemento, afirmando que, aunque es necesario que la cooperación se dirija el desarrollo de una función pública común entre las partes, ello no quiere decir que esta tenga que ser absolutamente coincidente. A su entender, también podría existir esta relación de colaboración administrativa cuando la actuación de una de las partes sea un complemento específico de las funciones de interés público de la otra (FJ 59). 
dicho acuerdo se rige exclusivamente por razones de interés público -y no de mercado-, sin que se sitúe a ninguna empresa privada en una situación privilegiada respecto de sus competidores ${ }^{32}$.

En todo caso, adquiriría ahora una especial relevancia la motivación o justificación de la utilización de dicho instrumento convencional, como elemento clave para justificar y controlar el recurso a esta figura. En efecto, si como hemos ido argumentando, el tratamiento contractual de estos negocios jurídicos podría modularse a partir de su elemento causal -esto es su orientación a la consecución de un específico interés público que excede de la materia contractual-, resulta más que nunca imprescindible que el convenio exponga de manera clara todas las circunstancias que habilitan su utilización, así como las finalidades de interés público que pretenden conseguirse con él.

\section{A MODO DE CONCLUSIÓN}

Para concluir brevemente nuestro trabajo podríamos destacar, en primer lugar, que la exposición del tratamiento contractual de los convenios interadministrativos nos ha permitido poner de relieve claramente la principal problemática que plantea hoy en día esta figura: mientras que, por un lado, se nos presentan como un mecanismo para garantizar a los Poderes Públicos la capacidad para poder gestionar eficazmente sus propias competencias y hacer efectivo el principio de colaboración administrativa, por el otro, al poder configurarse teóricamente como un contrato público a efectos de la normativa contractual, su régimen jurídico puede chocar, a veces, con la exigencia a nivel europeo de una economía de mercado altamente competitiva y con la necesidad de someter su régimen jurídico a los procedimientos de licitación previstos en el TRLCSP.

No obstante, hemos podido constatar también que la dificultad aparente de conjugar ambas perspectivas podría solventarse si atendemos a la finalidad de interés público que persiguen los convenios interadministrativos. En efecto, si entendemos que el principal objetivo perseguido por la legislación en materia de contratación pública se dirige esencialmente a garantizar la apertura y libre competencia en el mercado interior, podemos llegar a la conclusión de que debería darse un tratamiento diferenciado a aquellos negocios jurídicos

32 En este punto, además, conviene recordar que, como se ha apuntado en varias ocasiones -p. ej., Huergo Lora (2001, pp. 158 y 168-171), Bassols COMA (1988, p. 170) o VilaLTA REIXACH (2012, pp. 399-400)-, no existe en el ordenamiento jurídico español un principio general de subsidiariedad que obligue a la Administración Pública a remitir al mercado o a los particulares el desarrollo de cualquier actividad con trascendencia económica. Por lo que la libertad de empresa no incluiría dentro de su contenido preceptivo un deber de los Poderes Públicos de garantizar un determinado mercado a los empresarios privados en todos los sectores, y menos el deber de garantizar un determinado nivel de contratación con las administraciones (HuERGO LORA, 2001, pp. 168-171). 
-como los convenios entre administraciones públicas territoriales que hemos examinado-que, al margen de su objeto, se rigen por consideraciones ajenas al mercado y se dirigen exclusivamente a la consecución de unos objetivos de interés público compartidos por las partes intervinientes.

\section{BIBLIOGRAFÍA}

Ávila OrIVE, J. L. (2002). Los convenios de colaboración excluidos de la Ley de Contratos de las Administraciones Públicas. Madrid: Civitas.

BAÑo LEÓN, J. M. (2004). La influencia del derecho comunitario en la interpretación de la Ley de Contratos de las Administraciones Públicas. Revista de Administración Pública, n. ${ }^{\circ} 151$, pp. 11-38.

Bassols Coma, M. (1988). Constitución y sistema económico. 2. ${ }^{\text {a }}$ ed. Madrid: Tecnos.

Bernal Blay, M. A. (2006). Las encomiendas de gestión excluidas del ámbito de aplicación de la Ley de Contratos de las Administraciones Públicas. Una propuesta de interpretación del artículo 3.1 letra 1) el TRLCAP. Revista Española de Derecho Administrativo, n. ${ }^{\circ} 129$, pp. 77-90.

Bustillo Bolado, R. (2004). Convenios y contratos administrativos: transacción, arbitraje y terminación convencional del procedimiento. Navarra: Thomson Reuters-Aranzadi.

Díez Picazo, L. (1996). Fundamentos de Derecho Civil Patrimonial. Vol. I. 5. a ed. Madrid: Civitas.

Entrena Cuesta, R. (1957). Consideraciones sobre la teoría general de los contratos de la Administración. Revista de Administración Pública, n. ${ }^{\circ} 24$, pp. 39-74.

Gimeno Feliú, J. M. (2010). El ámbito objetivo de aplicación de la LCSP. Tipología contractual y negocios jurídicos excluidos. Cuadernos de Derecho Local, n. ${ }^{\circ} 22$, pp. 43-82.

Gimeno Feliú, J. M. (2015). La codificación de la contratación pública mediante el Derecho pretoriano derivado de la jurisprudencia del TJUE. Revista Española de Derecho Administrativo, n. ${ }^{\circ} 172$, p. 81-122.

GonZÁLEZ-Antón Álvarez, C. (2002). Los convenios interadministrativos de los entes locales. Madrid: Montecorvo.

Gosálbez Pequeño, H. (2000). El contratista de la Administración Pública. Madrid: Marcial Pons. 
Gracia Retortillo, R. y Vilalta Reixach, M. (2012). Las relaciones interadministrativas de las administraciones públicas de Cataluña. Comentarios a la Ley 26/2010, de 3 de agosto, de Régimen Jurídico y Procedimiento de las Administraciones Públicas de Cataluña. Madrid: Iustel, pp. 663-717.

Huergo LorA, A. (2001). La libertad de empresa y la colaboración preferente de las administraciones con las empresas públicas. Revista de Administración Pública, n. ${ }^{\circ}$ 154, pp. 129-171.

Martín Huerta, P. (2000). Los convenios interadministrativos. Madrid: Instituto Nacional de Administración Pública.

Martín-Retortillo Baquer, S. (1996). El Derecho Civil en la génesis del Derecho Administrativo. Madrid: Civitas.

Morell Ocaña, L. (1998). Curso de Derecho Administrativo, t. I. 3. a ed. Navarra: Aranzadi.

Pascual García, J. (2010). Las encomiendas de gestión a la luz de la Ley de Contratos del Sector Público. Madrid: Boletín Oficial del Estado (BOE).

Pascual García, J. (2012). Convenios de colaboración entre entidades públicas y convenios con administrados. Madrid: Agencia Estatal Boletín Oficial del Estado.

Pedersen, K. y Olsson, E. (2010). Commission vs. Germany - A new approach to in-house providing?. Public Procurement Law Review, n. ${ }^{\circ}$ 1, pp. 33-45.

Pernás García, J. J. (2008). Las operaciones in bouse y el Derecho comunitario de contratos públicos. Madrid: Iustel.

Piñar Mañas, J. L. (2004). El Derecho comunitario como marco de referencia del Derecho español de contratos públicos. Comentarios a la Ley de Contratos de las Administraciones Públicas. 2. ${ }^{a}$ ed. Madrid: Thomson-Civitas, pp. 27-79.

RazQuín Lizarraga, M. M. (1996). Contratos públicos y Derecho Comunitario. Navarra: Aranzadi.

Rodríguez de SAnTiago, J. M. (1997). Los convenios entre administraciones públicas. Madrid: Marcial Pons.

Santiago Iglesias, D. (2014). Los convenios interadministrativos. Contratos. Civiles, mercantiles, públicos, laborales e internacionales, con sus implicaciones tributarias. Navarra: Thomson Reuters-Aranzadi, pp. 891-937.

VIlalta ReiXaCH, M. (2012). La encomienda de gestión. Entre la eficacia administrativa y la contratación pública. Navarra: Thomson Reuters-Aranzadi. 
Vilalta ReiXaCH, M. (2014). Los llamados contratos de auto-provisión (o contratos in house providing). Contratos. Civiles, mercantiles, públicos, laborales e internacionales, con sus implicaciones tributarias. Navarra: Thomson Reuters-Aranzadi, pp. 940-990. 